\title{
Giải pháp nâng cao năng lực thích ứng với thay đổi của cán bộ quản lý trường đại học trong bối cảnh đổi mới giáo dục hiện nay ở Việt Nam
}

\author{
Đặng Xuân Hải", Đỗ Thị Thu Hằng \\ Truờng Đại học Giáo dục, ĐHQGHN, 144 Xuân Thủy, Cầu Giấy, Hà Nội, Việt Nam
}

Nhận ngày 10 tháng 3 năm 2017

Chỉnh sửa ngày 20 tháng 4 năm 2017; Chấp nhận đăng ngày 15 tháng 6 năm 2017

\begin{abstract}
Tóm tắt: Trong Tạp chí Khoa học Đại học Quốc gia Hà Nội (ĐHQGHN), Nghiên cứu Giáo dục, tập 32, số 3,2016 chúng tôi đã trình bày nội dung về "Thích ứng với thay đổi của cán bộ quản lí nhà trường đại học trong bối cảnh đổi mới GD hiện nay ở Việt Nam - Nghiên cứu trường hợp ở ĐHQGHN". Từ kết quả nghiên cứu đó chúng tôi đề xuất khung năng lực thích ứng của $\mathrm{CBQL}$ nhà trường đại học trong bối cảnh đổi mới ở Việt Nam hiện nay. Khung năng lực thích ứng của $\mathrm{CBQL}$ nhà trường chỉ rõ khả năng nhạy cảm với sự thay đổi, khả năng thẩu hiểu những tác động tích cực và tiêu cực của các thay đổi lên mình và nhà trường của mình, khả năng vượt qua thử thách của sự thay đổi một cách có hiệu quả nhất; đặc biệt khả năng thích ứng của một $\mathrm{CBQL}$ gắn rất nhiều với kỹ năng quản lí thay đổi ở đơn vị mình phụ trách.
\end{abstract}

Từ khóa: Nhận diện, Thích ứng, Khung năng lực thích ứng, Tiêu chí.

\section{1. Đặt vấn đề}

Đứng trước bối cảnh hội nhập ngày càng sâu rộng và nhiều thay đồi của xã hội và đồi mới giáo dục (GD), các cán bộ quản lí (CBQL) nhà trường nói chung và của trường đại học nói riêng cần có những thích ứng để phát triển. Trong Tạp chí Khoa học ĐHQGHN, Nghiên cứu Giáo dục, tập 32, số 3, 2016 [1] chúng tôi đã trình bày nội dung về "Thích ứng với thay đổi của cán bộ quản lí nhà trường đại học trong bối cảnh đổi mới GD hiện nay ở Việt Nam Nghiên cứu trường hợp ở ĐHQGHN" có đặt vấn đề cần xây dựng khung chuẩn năng lực thích ứng với các tiêu chí và các chỉ báo để nhận diện năng lực này ở các $\mathrm{CBQL}$ và tìm các giải pháp nâng cao năng lực thích ứng với thay đổi cho cán bộ quản lí trường đại học

\footnotetext{
Tác giả liên hệ. ĐT.: 84-967685905.

Email: haidx@vnu.edu.vn

https://doi.org/10.25073/2588-1159/vnuer.4079
}

trong bối cảnh đổi mới GD hiện nay ở Việt Nam. Bài viết này là sự tiếp tục của bài viết đã được công bố nêu trên.

\section{2. Đề xuất khung năng lực thích ứng cho cán bộ quản lí ở trường đại học}

Để có căn cứ khoa học đề xuất khung năng lực thích ứng cho cán bộ quản lí (CBQL) trường đại học $(\mathrm{DH})$ chúng tôi dựa vào kết quả nghiên cứu ở [1] và phân tích sâu một số quan điểm nhận diện khả năng thích ứng của $\mathrm{CBQL}$ nói chung và $\mathrm{CBQL}$ trường $\mathrm{ĐH}$ nói riêng của những người đi trước. Trong chuyên khảo của Heifetz, R. A., Linsky, M., \& Grashow, A. (2009) [2], thì khả năng thích ứng của một người có thể được nhận diện qua khả năng đồng hóa và thích nghi với thay đổi; nhận diện thông qua khả năng phân tích tác động của thay đồi lên bản thân và khả năng ứng phó chủ động với thay đổi của hoàn cảnh cũng như khả năng 
lường trước được hậu quả của hành động để tạo ra những thay đổi của chính mình nhằm đáp ứng được các yêu cầu thay đổi của bối cảnh...

Theo quan điểm ở "Tứ thư lãnh đạo" của Hòa Nhân [3] thì một người có khả năng thích ứng tốt nếu làm chủ được "Lục tri" (6 biết):

a. Tri kỷ, Tri bi (biết mình, biết người): Biết mình có điểm mạnh gì, điểm yếu gì để có ứng xử hợp lí với phương châm đã trở thành khẩu ngữ: "biết mình, biết người trăm trận trăm thắng".

b. Tri thời, Tri thế (biết thời, biết thế): Biết mình đang sống trong bối cảnh, thời đại nào và vị thế của mình trong bối cảnh đó để dự báo và sằn sàng thích nghi.

c. Tri túc, Tri chi (biết đủ, biết dừng): Biết tự thỏa mãn với cái mình có và lượng sức mình mà xử lí với phương châm được nêu ra từ thời Khổng Tử: "Biết đủ là đủ. Biết dừng đúng lúc".

Và từ đó cũng có thể cụ thể hóa thành các chỉ báo cho vận dụng "lục tri - 6 biết" vào thực tế cuộc sống và công việc để nhận diện khả năng thích ứng. Trong chương 9 của sách này [3] cũng nhấn mạnh: Thích ứng tốt, liên quan đến sự chuẩn bị nhận thức về bối cảnh thay đổi; liên quan đến chuẩn bị tâm thế đối mặt với sự thay đổi và chuẩn bị những điều kiện tối thiểu cho sự thay đổi..., phải "dĩ biến, ứng biến" tức là lấy thay đổi để ứng phó với thay đổi.
Như bài viết về "Thích ứng với thay đổi của cán bộ quản lí nhà trường đại học trong bối cảnh đổi mới GD hiện nay ở Việt Nam Nghiên cứu trường hợp ở ĐHQGHN" [1] chúng tôi đã nêu khả năng thích ứng của một người $\mathrm{CBQL}$ nói chung và $\mathrm{CBQL}$ nhà trường nói riêng phụ thuộc vào 4 yếu tố sau đây:

1. Nhận thức về các nội dung các thay đổi nói chung và nội dung của chủ trương"đổi mới căn bản toàn diện GD\&ĐT” liên quan trực tiếp đến cá nhân người $\mathrm{QL}$ và đơn vị của người đó đang QL;

2. Nhận diện, phân tích được các tác động, rào cản và thách thức khi triển khai các nội dung thay đổi ở đơn vị của mình;

3. Khả năng thích ứng với thay đổi của bản thân nhà $\mathrm{QL}$ nói riêng và của tổ chức mà họ đang điều hành;

4. Kỹ năng QL sự thay đổi của CBQL trong nhà trường của $\mathrm{CBQL}$ đó đang đảm nhiệm

Bước đầu khảo sát năng lực thích ứng của 280 đối tượng $\mathrm{CBQL}$ ở ĐHQGHN với những kết quả có tính thông kê về khả năng thích ứng của một số nhóm đối tượng $\mathrm{CBQL}$ cấp khoa và CBQL cấp phòng. Nghiên cứu đó cho phép rút ra một số kết luận khoa học cho việc xây dựng các chỉ báo về năng lực thích ứng cho $\mathrm{CBQL}$ ở trường đại học. Chúng tôi trình bày khung năng lực thích ứng với các tiêu chí và chỉ báo nhận diện cụ thể sau đây:

Bảng 1. Tiêu chí 1 và các chỉ báo nhận diện khả năng thích ứng của CBQLNT

\begin{tabular}{l}
\hline \\
\hline TIÊU CHÍ 1: Nhận thức được tác động của các nội dung thay đổi lên bản thân và đơn \\
vị mình đang qức cấp độ \\
1. Nhận diện được những bất cập của mình và đơn vị của mình khi bối cảnh thay đổi; \\
2. Thâu hiểu được các yêu cầu phải thay đổi để bản thân và đơn vị thích nghi với thay \\
đổi của bối cảnh; \\
3. Nhận diện được các nội dung cụ thể của đích phải đến khi thực hiện các thay đổi ở \\
đơn vị mình phụ trách; \\
4. Thấu hiểu được tính chất, đặc điểm, quy mô của sự thay đổi mà mình phải đối mặt; \\
5. Thấu hiểu được bản chất của các khía cạnh của sự thay đổi mà mình định tiến hành; \\
6. Xác định các yếu tố liên quan trực tiếp với nội dung thay đổi mà mình định tiến \\
hành ở đơn vị;; \\
7. Dự kiến được lộ trình có tính khoa học để thực hiện sự thay đổi mà mình định tiến \\
hành ở đơn vị với độ hợp lí cao.
\end{tabular}


Bảng 2. Tiêu chí 2 và các chỉ báo nhận diện khả năng thích ứng của CBQLNT

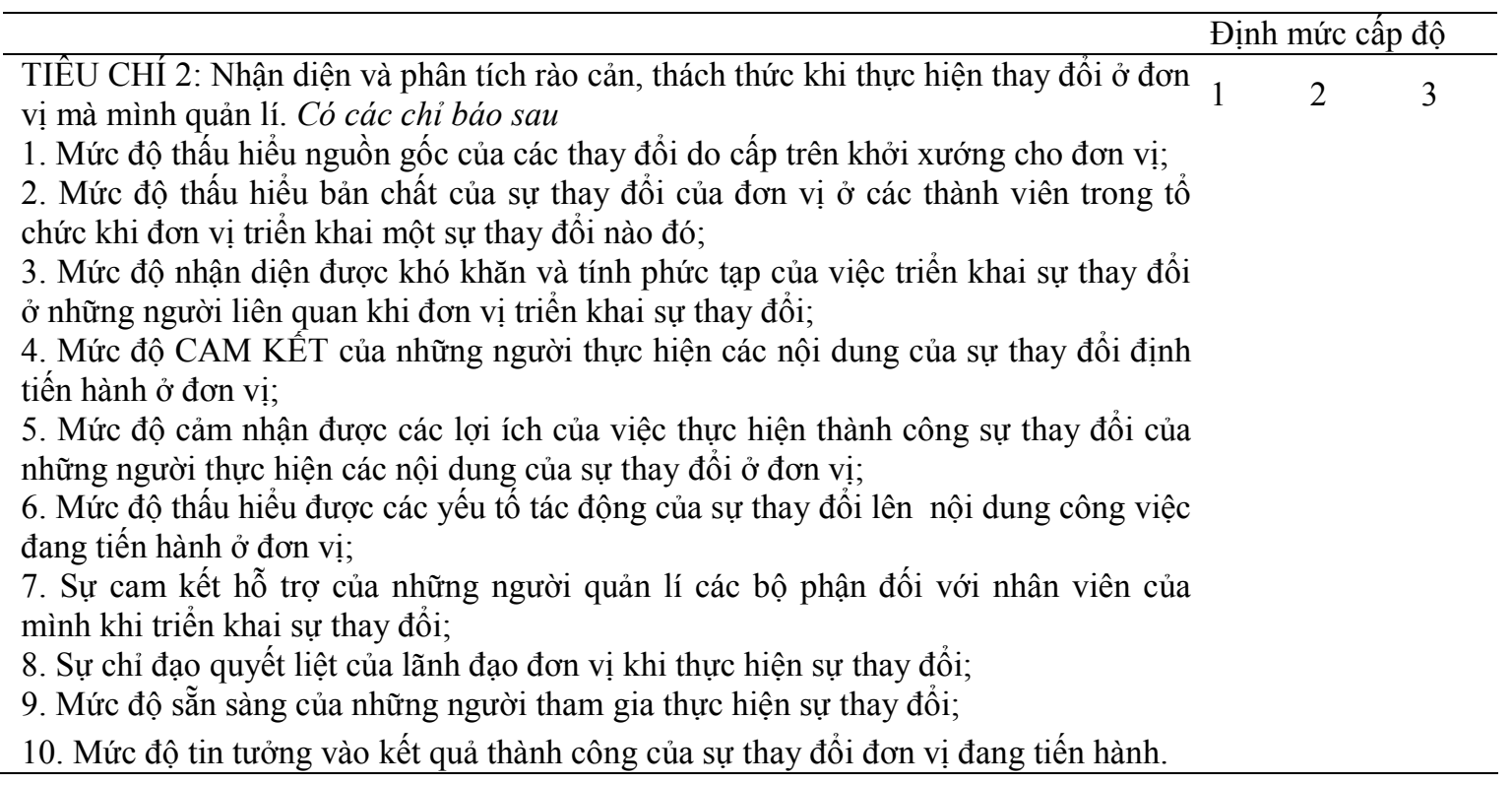

Bảng 3. Tiêu chí 3 và các chỉ báo nhận diện khả năng thích ứng của $\mathrm{CBQL}$ nhà trường

Định mức cấp độ

TIÊU CHÍ 3: Khả năng hành động và kỹ năng thích ứng với thay đổi với tư cách là người quản lí đơn vị. Có các chỉ báo sau:

1. Tận dụng được sự hỗ trợ của các bên liên quan khi thực hiện sự thay đổi ở cơ sở $\mathrm{G}$. mình;

2. Phân cấp hợp lí trong việc thực hiện các nội dung thay đổi ở đơn vị;

3. Người quản lí làm chủ được "Lục tri" (6 biết);

4. Nhận diện được đặc điểm bản thân và thách thức của bối cảnh mình đang tồn tại;

5. Có khả năng thấu hiểu các phản ứng khi khởi xướng sự thay đổi và hóa giải các xung đột khi thực hiện sự thay đổi;

6. Mức độ hiểu biết về văn hóa và các giá trị của tổ chức mình như là các yếu tố quan trọng để sẵn sàng thích nghi với mỗi thay đổi;

7. Phân tích tình huống và xử lí chúng khi gặp phải trong quá trình thực hiện thay đổi;

8. Phân tích các phản hồi tích cực hay tiêu cực từ những người liên đới để có xử lí hợp lí;

9. Lắng nghe một cách cởi mở và chăm chú khi mọi người trình bày ý tưởng của họ, ngay cả khi không đồng ý;

10. Có khả năng thuyết phục cấp dưới tin tưởng vào kết quả tích cực của sự thay đổi;

11. Làm tốt công tác truyền thông về sự thay đổi để tạo lập sự đồng thuận của những người liên đới;

12. Lựa chọn thứ tự ưu tiên khi thực hiện thay đổi định tiến hành theo lộ trình và điều kiện triển khai. 
Bảng 4. Tiêu chí 4 và các chỉ báo nhận diện khả năng thích ứng của CBQLNT

TIÊU CHÍ 4: Kỹ năng QL thay đổi; Có các chỉ báo sau:

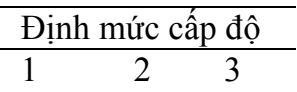

1. Người $\mathrm{CBQL}$ khuyến khích những người khác trong đơn vị có các ý tưởng và phương pháp mới;

2. Người CBQL thường xuyên chia sẻ thông tin để tạo điều kiện phối hợp cho thay đổi đạt kết quả mong muốn;

3. Người CBQL luôn cải thiện các quá trình thực hiện thay đổi để đạt được kết quả mong muốn của một sự thay đổi;

4. Người CBQL làm cho mọi người trong đơn vị cảm thấy thoải mái với sự thay đổi trước khi quyết định tiến hành một thay đồi liên quan đến hoạt động chính của đơn vị mình;

5. Nếu cái gì đó phải được thay đổi, người quản lí bắt đầu cân nhắc và lên kế hoạch để hiện thực nó ngay lập tức, không tranh luận nhiều;

6. Người $\mathrm{CBQL}$ thúc đẩy ý thức cạnh lành mạnh khi thực hiện các nội dung của sự thay đổi;

7. Người $\mathrm{CBQL}$ chắc chắn rằng tất cả cán bộ, $\mathrm{GV}$ rõ ràng về các chính sách, giá trị và mục tiêu của trường mình khi thực hiện thay đổi;

8. Người $\mathrm{CBQL}$ tạo điều kiện thuận lợi và môi trường thân thiện để các đồng nghiệp cũng như cấp dưới học hỏi và giúp nhau phát triển trong thay đổi;

9. Người CBQL Phối hợp thường xuyên với các nhà quản lý ở các bộ phận khác trong trường để tổ chức thực hiện thay đổi;

10. Người $\mathrm{CBQL}$ chú ý việc huấn luyện cấp dưới nâng cao kỹ năng thực hiện nhiệm vụ của mình để họ có thể đạt được kết quả cao hơn khi đối mặt với thay đổi;

11. Người lãnh đạo dám chấp nhận, dám đương đầu với đổi mới, chấp nhận rủi ro;

12. Người lãnh đạo phải lựa chọn những nội dung đổi mới để làm, phải quyết tâm làm đến cùng;

13. Người lãnh đạo đưa ra sáng kiến, biết tập hợp nguồn lực, tập hợp quần chúng hỗ trợ;

14. Người $\mathrm{CBQL}$ có phương pháp đánh giá kết quả thay đổi chính xác, khách quan để ghi nhận hiệu quả của sự thay đổi đã đạt được;

15. Biểt phân bố nguồn lực ưu tiên cho các thay đổi có tác động lớn đến thương hiệu nhà trường.

Bảng 5. Nhận diện bậc của khả năng thích ứng với thay đổi của một CBQLNT

\begin{tabular}{lllll}
\hline BẬC & 1 & 2 & 3 & 4 \\
\hline Yếu tố 1 & Từ 7-10 điểm & Từ 11-15 điểm & Từ 16-18 điểm & Từ 18-21 điểm \\
Yếu tố 2 & Từ 10-13 điểm & Từ 14-19 điểm & Từ 20-26 điểm & Từ 27-30 điểm \\
Yếu tố 3 & Từ 12-15 điểm & Từ 16-23 điểm & Từ 24-33 điểm & Từ 34-36 điểm \\
Yếu tố 4 & Từ 15-20 điểm & Từ 21-30 điểm & Từ 31-40 điểm & Từ 41-45 điểm \\
Tổng & Từ 44-58 điểm & Từ 62-87 điểm & Từ 91-107 điểm & Từ 120-132 điểm \\
\hline
\end{tabular}

Định mức cấp độ cho việc tự đánh giá hay đánh giá mức độ khả năng thích ứng: (1) đạt được dưới $40 \%$ nội dung của tiêu chí; (2) đạt được 40-70\% nội dung của tiêu chí;(3) đạt được trên $70 \%$ nội dung của tiêu chí.
Cấp độ để nhận diện năng lực thích ứng: Khi CBQL nhà trường muốn tự đánh giá hay được đánh giá căn cứ vào mức độ ở từng tiêu chí theo phần trăm có được khi so sánh khả năng thực hiện các chỉ báo có trong từng nội dung của tiêu chí và định mức cấp độ của khả 
năng thích ứng của mình hay của đơn vị mình đang phụ trách. Cũng có thể nhận diện năng lực thích ứng bằng cách đánh dấu vào mức độ 1-2-3 ở từng chỉ báo: 1 điểm có ở mức thấp (chỉ báo này không thể hiện rõ ở bản thân hay ở đơn vị mà mình đang quản lí hoặc chỉ thể hiện dưới 40\% khía cạnh nội dung chỉ báo); 2 điểm có ở mức trung bình (chỉ báo này thể hiện không thật rõ ở bản thân hay ở đơn vị mà mình đang quản lí hoặc chỉ thể hiện 40-70\% khía cạnh nội dung chỉ báo) và 3 là điểm tối đa (chỉ báo này thể hiện rất rõ ở bản thân hay ở đơn vị mà mình đang quản lí hoặc thể hiện trên $70 \%$ khía cạnh nội dung chỉ báo). Căn cứ vào điểm tổng sẽ đánh giá "mức độ của khả năng thích ứng với thay đổi” trong tháng đánh giá khả năng thích ứng gồm 4 bậc.

Nhìn vào bảng mô tả trên cho thấy nếu tổng (cộng dồn điểm của cả 4 tiêu chí với 44 chỉ báo) điểm dưới 58 điểm, điều đó có nghĩa là CBQL đó có khả năng thích ứng với thay đổi thấp (hay ở bậc 1 trong 4 bậc). Nếu tổng điểm trong khoảng 59-87 điểm, điều đó có nghĩa là $\mathrm{CBQL}$ đó có khả năng thích ứng trung bình (hay ở bậc 2 trong 4 bậc); nếu tổng điểm từ 88-107, điều đó có nghĩa là CBQL đó có khả năng thích ứng với thay đổi khá cao (hay ở bậc 3 trong 4 bậc); nếu tổng điểm trên 120 điểm điều đó có nghĩa là $\mathrm{CBQL}$ đó có khả năng thích ứng cao nhất (hay ở bậc 4 trong 4 bậc).

Khung năng lực được xây dựng dựa trên kết quả nghiên cứu của [1] tức là dựa vào kết quả điều tra của 280 khách thể khảo sát. Tuy nhiên để khẳng định tính khả thi, chúng tôi đã phỏng vấn sâu về một số điểm nhấn của khung năng lực đã đề xuất đối với CBQL ở các đơn vị đã khảo sát bằng phiếu. Khách thể phỏng vấn gồm $10 \mathrm{CBQL}$ cấp khoa, phòng và 2 thủ trưởng ở 2 trường đại học thành viên của ĐHQGHN. Vì khuôn khổ của một bài báo chúng tôi không thể trình bày hết ý kiến trả lời phỏng vấn. Nói chung các ý kiến phỏng vấn đều ghi nhận các tiêu chí và chỉ báo do chúng tôi đề xuất; một số ý kiến nhấn mạnh điều tâm đắc.
- Khi chúng tôi hỏi "chỉ báo nào trong khung khả năng thích ứng của $\mathrm{CBQL}$ khi có thay đổi đồng chí ấn tượng nhất?”; PGS.TS Lê, hiệu trưởng (HT) một trường đại học thành viên đã chia sẻ: "Muốn thay đổi thành công (liên quan đến khả năng lực thích ưng của một $C B Q L), C B Q L$ phải biết thuyết phục cán bộ, nhân viên của minh,làm sao để ho nhận thấy chính ho cần phải thay đổi, và chính ho cunng là người tham gia đề xuất và tích cưc tham gia thực hiện sụ thay đổi đó".

- Khi chúng tôi hỏi câu hỏi tương tự với PGS.TS Nguyễn, HT một trường đại học thành viên khác, đồng chí này đã chia sẻ: "Người lãnh đạo dám chấp nhận, dám đương đầu với đổi mới, chấp nhận rủi ro; Người lãnh đạo phải lựa chọn những nội dung đổi mới để làm, phải quyết tâm làm đến cùng; người lãnh đạo đưa ra sáng kiến, biết tập hợp nguồn lực, tập hợp quần chúng hỗ trợ". Và câu hỏi: Xin cho biết cách đánh giá khả năng thích ứng của một $\mathrm{CBQL}$ ở đơn vị nơi ông đang quản lí? Câu trả lời là:"Nền tảng của năng lực thích ứng gắn với tinh thần trách nhiệm, có trình độ chuyên môn, nghiệp vụ; có hiểu biết và nhận thức đúng đắn về sự thay đổi; có độ nhạy bén với cái mới, sã̃n sàng đối mặt với thay đổi. Nó cũng thể hiện ở tinh thần cầu thị; biết chia sẻ, hợp tác, thuyết phục, phát hiện điểm mạnh. Biết nhìn người, dám tin người, biết ngoại ngữ (tiếng Anh), có khả năng chịu áp lực cao... Thực sự hành động để tạo niềm tin đối với nhân viên" (PGS.TS. HT).

Kết quả nghiên cứu được trình bày ở [1] và phỏng vấn sâu ở đây về khung năng lực thích ứng cho phép chúng tôi đưa ra những kết luận: Để nâng cao khả năng thích ứng của $\mathrm{CBQL}$ nhà trường đại học trong bối cảnh đổi mới ở Việt Nam hiện nay, người $\mathrm{CBQL}$ nhà trường phải có nhạy cảm với sự thay đổi, có khả năng thấu hiểu những tác động tích cực và tiêu cực của các thay đổi lên mình và nhà trường của mình, có khả năng vượt qua thử thách của sự thay đổi một cách có hiệu quả nhất; đặc biệt khả năng 
thích ứng của một $\mathrm{CBQL}$ gắn rất nhiều với kỹ năng quản lí thay đổi ở đơn vị mình phụ trách.

\section{Một số giải pháp tăng cường năng lực thích ứng cho $\mathrm{CBQL}$ nhà trường nói chung, trường đại học nói riêng}

Trên cơ sở "khung năng lực thích ứng" cho một $\mathrm{CBQL}$ nhà trường nói chung, ở trường $Đ H$ nói riêng ở trên, cần triển khai các giải pháp sau để nâng cao năng lực thích ứng cho $\mathrm{CBQL}$ nhà trường nói chung và $\mathrm{CBQL}$ trường $\mathrm{ĐH}$ nói riêng.

Giải pháp 1: Quán triệt cho moi cán bộ quản lí nhà truờng khung năng lực thích úng; yêu cầu mỗi người tự xác định mức độ năng lực thich ưng của bản thân khi thực hiện sụ thay đổi ở co sở giáo duc của mình.

Khung năng lực là bảng tham chiếu để một $\mathrm{CBQL}$ nhà trường nói chung, trường đại học nói riêng nhận diện khả năng thích ứng với thay đổi. Trước tiên xem xét 4 tiêu chí nhận diện mình đang có ở mức độ nào và để biết được nội dung từng tiêu chí và nghiên cứu các chỉ báo được mô tả trong mỗi tiêu chí đó. Trên cơ sở xem xét "khung năng lực thích ứng" cho một $\mathrm{CBQL}$ nhà trường nói chung, ở trường $\mathrm{ÐH}$ nói riêng, đối chiếu với bản thân và hoạt động ở đơn vị mình đang quản lí để xác định các yếu tố liên quan đến khả năng thích ứng mình đang có hoặc phải bổ sung; cũng có thể dựa vào khung năng lực thích ứng để cụ thể hóa những vấn đề mình cần quan tâm hay cần tìm hiểu sâu để vận dụng vào thực tế triển khai các thay đổi cho đơn vị mình nhằm đáp ứng các yêu cầu đổi mới GD hiên nay. Khi thực hiện biện pháp này cần lưu ý một số điểm:

Muốn có khả năng thích ứng phải không ngừng hoàn thiện khả năng "phản xạ" với những cái mới trên cơ sở phân tích, dự báo tốt. Tầm nhìn là phương tiện cho công tác dự báo và cũng là điều kiện tạo khả năng thích ứng cho một cán bộ quản lí trong bối cảnh luôn thay đổi.Khả năng dự báo và xây dựng tầm nhìn cuả một $\mathrm{CBQL}$ nhà trường liên quan đến việc phân tích các xu thế chủ đạo của kinh tế xã hội tác động lên cơ sở GD của mình; nhận diện được yều cầu cụ thể của giai đoạn phát triển của đất nước để khi triển khai các hoạt động GD\&ĐT hay thực thi quản lí nhà trường; xác định đúng "hệ quy chiếu" mình đang vận hành. Các nhà quản lí giáo dục nói chung, quản lí nhà trường nói riêng phải có tư duy của quản lí thay đổi khi xử lí các bài toán đang đặt ra. Muốn có năng lực dự báo và khả năng thích ứng cần nhiều yếu tố trong đó có yếu tố quan trọng là tầm nhìn và khả năng điều chỉnh bản thân. Tầm nhìn đối với một người quản lí có thể có nếu họ luôn nắm bắt được xu thế phát triển của đối tượng quản lí của họ và sự thay đổi của bối cảnh. Muốn có được những điều trên họ cần không ngừng tích lũy hiểu biết và luôn có tư duy mở để đón nhận những thay đổi.

Nội dung bồi dưỡng "năng lực thích ứng" cho $\mathrm{CBQL}$ nhà trường bám sát các tiêu chí, chỉ báo được nêu ra trong "khung năng lực thích ứng" này.

Giải pháp 2: Huấn luyện một số kỹ năng cần thiết liên quan đến năng lục thích ưng cho CBQL nhà trường khi đối mặt với các yêu cầu phải thay đổi trong bối cảnh đổi mới $G D$ hiện nay.

Theo chúng tôi, muốn nâng cao khả năng thích ứng $\mathrm{CBQL}$ cần được huấn luyện để hoàn thiện một số kỹ năng sau:

1/ Kỹ năng nhận diện bản thân, nhận diện nhà trường hiệu quả và bối cảnh tồn tại của nhà trường mình đang quản lí khi tiếp nhận sự thay đổi

a) Muốn nhận diện được sự thay đổi tác động lên bản thân mình, phải biết nhìn lại mình và phân tích bối cảnh mình đang sống

- Nhìn lại mình chính là sự thấu hiểu sâu sắc về bản thân và môi trường tồn tại của bản thân; nhận ra được những điểm yếu và điểm mạnh, nhu cầu, giá trị và mục tiêu của bản thân để tạo khả năng thích ứng với sự thay đổi. Điềm tĩnh đón nhận thay đổi (Kiểm soát được cảm xúc, khả năng chuyển chúng thành trạng thái tích cực...) và luôn khao khát thử thách cái mới... Phân tích bối cảnh mình đang sống chính là việc xem xét môi trường pháp lí, môi trường làm việc và các yếu tố khác (thậm chí cả 
cái gọi là "cơ chế”) chi phối cuộc sống, công việc của mình để thấy trong bối cảnh đó buộc mình phải có những điều chỉnh để thích ứng với môi trường, bối cảnh đã thay đổi (điều chỉnh thói quen, điều chỉnh phong cách sống, làm việc, quản lí...).

- Một nhà trường hiệu quả là trường nhận ra các khiếm khuyết của mình, sẵn sàng tìm nguyên nhân và giải pháp, thường xuyên đánh giá, chấp nhận phê bình và điều chỉnh mục tiêu nhằm đáp ứng nhu cầu của người học và xã hội. Trên thực tế có những trường thích ứng tốt hơn các trường khác là do họ đội ngũ có khả năng thích ứng tốt hơn. Phương hướng hoạt động của nhà trường sẽ không thể thực hiện được trừ khi quy trình thông tin, trao đổi và ra quyết định được xây dựng hoàn chỉnh. Cải tiến qui trình của một trường học là một phần quan trọng trong quản lý thay đổi. Thay đổi nội dung chương trình cần đến sự thay đổi về thái độ, kiến thức và kỹ năng của giáo viên và của người lãnh đạo cơ sở GD đó. Nội dung chương trình tốt nhất sẽ trở thành vô dụng nếu giáo viên không tự giác thực hiện, không hiểu nội dung, thiếu kỹ năng hoặc không ủng hộ việc thực hiện chương trình một cách có hiệu quả. Để làm tốt điều nêu trên $\mathrm{CBQL}$ nhà trường phải có khả năng thích ứng tốt và truyền cảm hứng cho $G V$ của trường mình.

b) Muốn nhận diện được sự thay đổi của bối cảnh tác động lền nhà trường mình đang quản lí trước hết phải "biết phân tích SWOT" (SWOT: $\mathrm{S}-\mathrm{Manh}$; W-Yếu của đơn vị/nhà trường; $\mathrm{O}$ - thời co; T-Thách thức từ bối cảnh):

Khi phân tích SWOT (S-Mạnh; W-Yếu của đơn vị; O- thời cơ; T-Thách thức từ bối cảnh) thì $\mathrm{SW}$ được gọi là yếu tố bên trong của một tổ chức/nhà trường; OT được coi là yếu tố bên ngoài từ bối cảnh, môi trường. $\mathrm{S}$ chính là lợi thế, mặt mạnh của tổ chức/nhà trường mình; $\mathrm{W}$ chính là "yếu thế", mặt hạn chế của tổ chức/nhà trường mình; $\mathrm{O}$ là thời cơ, cơ hội đang tồn tại từ bối cảnh, môi trường đối với tổ chức/nhà trường mình; $\mathrm{T}$ là nguy cơ, thách thức, trở ngại mà tổ chức/nhà trường có thể phải đối mặt với tác động từ môi trường. Tất cả yếu tố trên có tính "động”, tương đối trong một thời điểm xác định và cơ sở dữ liệu phải là tập hợp các chỉ số liên quan đến các yếu tố của SWOT. Khi phân tích SWOT cần quan tâm đến cặp SO; WO; ST; WT để tìm ra các "chiến lược" hay các "dữ kiện" cần thiết cho dự báo, nhận diện được sự thay đổi tác động lên nhà trường mình đang quản lí.

2/ Kỹ năng hóa giải các tác động không mong muốn lên bản thân và lên nhà trường mình đang quản lí khi tiếp nhận sự thay đổi

Thông thường khi có sự thay đổi thường xuất hiện các rào cản sau và nó có thể gây những tác động không mong muốn lên sự phát triển của nhà trường, đó là những yếu tố:

Yếu tố tâm lí: sức ỳ lớn, bảo thủ, ngại thay đổi, sợ thất bại...

Yếu tố nhận thức: thiếu hiểu biết về nội dung "cái thay đổi", không có khả năng thực hiện thay đổi...

Yếu tố lợi ích: đụng chạm lợi ích, sợ mất "giá trị", tốn công sức...

Yếu tố nguồn lực (nhân lực, vật lực, tài lực, tin lực, thời lực...): điều kiện tối thiểu để triển khai không có, thiếu thông tin, thiếu sự hỗ trợ, thiếu động lực để thay đổi;

Yếu tố môi trường: thiếu đồng bộ, không được sự đồng thuận của những người liên quan, văn hóa tổ chức kém, môi trường niềm tín thiếu...

Yếu tố QL: Người QL thiếu năng lực cần thiết cho quản lí thay đổi thành công ...

Cần có những kỹ năng ứng xử với những vấn đề nêu trên:

- Nếu súc ỳ lớn, bảo thủ, ngai thay đổi, sợ thất bại...: Hãy tạo điều kiện cho GV, nhân viên của mình thời gian đủ để thử nghiệm cái mới, tạo môi trường niềm tin vào kết quả của sự thay đổi để họ “dám nghĩ, dám làm” và họ tin là họ được các cấp quản lí hỗ trợ khi gặp khó khăn.

- Nếu thiếu hiểu biết về nội dung "cái thay đổi”, không có khả năng thực hiện thay đổi: Hãy bổ sung kiến thức kỹ năng cho những người tham gia sự thay đổi; mời chuyên gia tư vấn hỗ trợ và đặc biệt chuẩn bị điều kiện tối thiểu để thay đổi có thể thành công.

- Nếu đụng chạm lợi ich, sợ mất "giá trị", tốn công sức... hãy cho những người tham gia 
sự thay đổi thấy giá trị và lợi ích của sự thay đổi và cho họ thấy xứng đáng để đầu tư công sức cho sự thay đổi. Nếu thay đổi thành công nhà trường sẽ phát triển và lợi ích của cộng động xã hội, của nhà trường, của những người tham gia sự thay đổi sẽ được đền đáp.

- Nếu điều kiện tối thiểu để triển khai không có, thiếu thông tin, thiếu sư hỗ trợ, thiếu động lực để thay đổi: Hãy làm cho những người tham gia sự thay đổi thấy rằng những điều kiện tối thiểu cho việc thực hiện thay đổi sẽ được đáp ứng (và đây là nhiệm vụ của người quản lí sự thay đổi). Họ sẽ được tạo động lực bằng việc đáp ứng nhu cầu chính đáng và được tưởng thưởng cho những kết quả đạt được; họ được cung cấp mọi thông tin cần thiết, kịp thời và được xử lí những vướng mắc trong điều kiện cụ thể của vấn đề đang thực hiện thay đổi.

- Nếu môi trường hoạt động thiếu đồng bộ, không được sự đồng thuận của những người liên quan, văn hóa tổ chức kém, môi trường niềm tin thiếu: Hãy cho những người tham gia thực hiện thay đổi tin rằng những vấn đề trong "tầm với" của người lãnh đạo đơn vị sẽ được cố gắng thực hiện (CBQL phải thuyết phục những người liên đới lợi ích của sự thay đổi, sẽ phát huy vai trò "đầu mối quan hệ" để huy động cộng đồng cho sự thay đổi...). Nhà trường sẽ chú trọng xây dựng văn hóa nhà trường là "văn hóa của một tổ chức biết học hỏi”, ở đó có phong cách lãnh đạo dân chủ, có công khai, minh bạch và có tính nhân văn cao và mọi người được tạo điều kiện môi trường cho việc tự khảng định mình, ở đó "Mọi người vì nhau và cũng vì sự phát triển của nhà trường"...

- Nếu người QL có khả năng thích úng kém, thiếu năng lực cần thiết cho QL thay đổi, uy tín thấp: người quản lí phải là người ham học hỏi và luôn tận dụng các cơ hội để nâng cao trình độ, năng lực của mình, làm chỗ dựa cho $G V$ và nhân viên của mình; nâng cao uy tín của mình thông qua những quyết định sáng suốt trên cơ sở làm chủ được thông tin và có những hiểu biết về những thay đổi mà nhà trường phải tiếp nhận; coi trọng phong cách quản lí dân chủ, hiệu quả trên cơ sở nhận thức uy tín không phải chỉ được tạo ra bởi "uy quyền" mà trước hết phải có "uy danh" và muốn có "uy danh" bản thân phải luôn học hỏi, phấn đấu trở thành "con chim đầu đàn"... Lập kế hoạch một cách linh hoạt, không xa rời thực tế, đặc biệt phải tôn trọng tư duy của duy vật biến chứng để tránh duy ý chí khi vạch kế hoạch và đặt mục tiêu cho bất kỳ sự thay đổi nào và khi quản lí thay đổi cần lưu ý tính đi lên trong cân bằng động với yêu cầu của bên trong và bên ngoài để duy trì bền vững kết quả đạt được theo một chiến lược dài hơi hơn.

CBQL phải biết tụ tạo động lực cho bản thân và biết tạo động lực cho $G V$, nhân viên: Bản thân người CBQL khao khát thành công để đạt được mục tiêu của bản thân mình và của nhà trường, liên tục phấn đấu đạt được sự tiến bộ đối mục tiêu đầy thách thức mà bản thân đặt ra; luôn luôn quan tâm đến cảm xúc của người khác; thân thiện, định vị tốt trong giao tiếp, giỏi trong việc tìm ra những điểm chung và xây dựng quan hệ... Có khả năng thuyết phục và cộng tác tốt... CBQL phải là người tạo động lực tốt cho $\mathrm{GV}$ thông qua kỹ năng đánh giá chính xác, khách quan, công bằng những kết quả của $G V$ và nhân viên; tạo môi trường làm việc đầy hứng khởi và quan tâm tối đa tới họ, sẵn sàng đáp ứng các yêu cầu chính đáng của họ nếu trong tầm với của mình.

3/ Kỹ năng tận dụng các mối quan hệ để hóa giải các tác động không mong muốn lên bản thân và lên nhà trường mình đang quản lí khi tiếp nhận sự thay đổi

Quan hệ công tác liên quan quy định về điều kiện làm việc, quy trình xử lí công việc, cách thức xử lí các xung đột về sự không đồng thuận. Khả năng tận dưng các mối quan hệ đòi hỏi phải có năng lực về quản lí sự đa dạng (như chấp nhận các quan điểm khác nhau khi nhìn nhận một sự vật hiện tượng và cần phải trao đổi để thống nhất quan điểm chung, không thành kiến với các vấn đề về tôn giáo, giới tính...) và có năng lực thuyết phục và đàm phán để xử lí những vấn đề chưa đồng thuận trong quan hệ công tác. Chúng ta đều biết, mọi thay đổi của nhà trường, của GD ảnh hưởng lên nhiều người và có sự quan tâm của toàn xã hội. Tính đa lợi ích và quan hệ đa chiều khi nói về các kết quả 
của giáo dục nói chung, của một nhà trường nói riêng buộc những người tham gia quản lí nhà trường cần tận dụng các mối quan hệ trong tổ chức thực hiện mục tiêu GD. Đây là một nét đặc trưng cần nhận diện khi thực hiện và quản lí thay đổi với một cơ sở GD\&ĐT. Kết quả của mọi thay đổi ở một nhà trường, trong GD khó có hiệu ứng tức thì và khó đo lường. Nhiều khi nhận diện kết quả thay đổi phải thông qua nhiều yếu tố liên quan. Đây là một nét đặc trưng tiếp theo cần nhận diện khi thực hiện và quản lí thay đổi với một nhà trường và nó cũng là một chỉ báo của năng lực thích ứng của $\mathrm{CBQL} N \mathrm{NT}$.

Các mối quan hệ, kết nối nhu cầu và sự đồng thuận là một trong những "nguồn lực" quan trong trong quản lí thay đổi, cần lưu ý tạo điều kiện trao đổi thông tin về những thay đổi mà nhà trường dự định hay đang thực hiện với những người liên đới. Cần đảm bảo rằng tất cả mọi nhân viên đều nhận được thông tin liên quan đến nội dung thay đổi mà mình được yêu cầu thực hiện và hiểu về chủ trương của cấp trên cũng như của nhà trường. Thông tin đầy đủ cho nhân viên, học sinh phụ huynh và cấp trên khi có điều kiện về kế hoạch thay đổi của trường.

4/ Kỹ năng hóa giải các xung đột khi tiếp nhận sự thay đổi

Khả năng thích ứng của người $\mathrm{CBQL}$ liên quan đến khả năng xử lí xung đột khi thực hiện các thay đổi. Người $\mathrm{CBQL}$ phải biết đánh giá tình hình trên cơ sở nhận biết những mặt mạnh, mặt yếu của trường mình, nắm bắt được trạng thái tâm lí của đội ngũ $\mathrm{GV}$ của trường mình cũng như khả năng của họ để lựa chọn các giải pháp tối ưu trong điều kiện cụ thể của trường mình nhằm tạo bầu không khí tin tưởng và chia sẻ, bao dung; đặc biệt có tiếp cận mềm dẻo trên cơ sở xác định đúng nguyên nhân khi giải quyết các xung đột nếu có.

- Cách đối mặt với xung đột mức "cá nhân" với tổ chức hay với chủ trương đổi mới: Chú ý tạo môi trường cho việc "cam kết cá nhân" với sự thay đổi liên quan đến cá nhân; quan tâm đến phát triển cá nhân và kịp thời hỗ trợ họ; tăng cường đối thoại và coi trong vai trò trọng tài khi giải quyết các lợi ích cá nhân và liên kết lợi ích (ta có phương châm "hài hòa 3 lợi ích") trong quá trình thực hiện thay đổi.

- Cách đối mặt với xung đột mức "nhóm" với tổ chức hay với chủ trương đổi mới: Chú ý "thay đổi phong cách lãnh đạo" của người quản lí sự thay đổi, người hiệu trường phải không ngừng học hỏi, nâng cao năng lực thích ứng và làm tốt 5 vai trò sau: Vai trò người cỗ vũ, "xúc tác" kích thích sự thay đổi; Vai trò người hỗ trợ suốt quá trình sự thay đổi; Vai trò người xử lí tốt các tình huống xẩy ra trong quá trình thay đổi; Vai trò người liên kết các nguồn lực cho sự thay đổi; Vai trò người duy trì sự ổn định trong sự thay đổi; đồng thời chú ý tăng cường tính đồng đội; chú ý đối thoại công khai.

- Cách đối mặt với xung đột mức "tổ chức" với chủ trương đổi mới: Chú ý "điều kiện thực hiện"; "phân tích kỹ hơn chiến lược hành động"; coi trọng công tác truyền thông, nên hội thảo rộng rãi về khả năng thực hiện, việc coi trọng tính phù hợp, thích ứng với hoàn cảnh và điều kiện nguồn lực mà đơn vị mình có thể khai thác được trong trường hợp này là rất quan trọng.

Muốn hóa giải xung đột trong quá trình thay đổi phải biết rõ nguyên nhân gây ra xung đột đó. Có 2 nguyên nhân thường gặp, thứ nhất xuất phát từ thiếu nhận thức, kỹ năng và ít đồng thuận khi thực hiện thay đổi; thứ 2 xuất phát từ điều kiện, nguồn lực và kéo theo là va chạm lợi ích khi triển khai thay đổi. Để hoá giải xung đột cần dự báo nhiều yếu tố, phải có kiến thức và kỹ năng của tâm lí học giao tiếp và tâm lí học quản lí. Để giảm thiểu xung đột cần lưu ý một số ý sau:

+ /Nhận diện được các mức độ phản ứng và phân biệt phản ứng tích cực và tiêu cực ở các đối tượng khác nhau khi tiến hành thay đổi.

+ /Nhận diện và giải thích được rõ ràng sự thay đổi (nội dung-đặc điểm, tính chất...) vì cần lưu ý rằng nếu chưa hiểu được bản chất của sự thay đổi thì khó chỉ đạo được mọi người thực hiện thay đổi.

+/Biết cách lôi kéo được mọi người tham gia vào sự thay đổi và biết bảo vệ nhân viên của mình khi họ vấp ngã (bước đầu họ có thể chưa quen với cái mới). 
Khả năng hoá giải xung đột trong quá trình thay đổi liên quan đến kỹ năng phát hiện và xử lí các mâu thuẫn khi nó mới hình thành và nếu nó đã trở thành xung đột cần sử dụng các "cách" xử lí mà sách "tâm lí học quản lí" đã đề cập; ở đây chúng tôi chỉ nêu một số khía cạnh liên quan đến kỹ năng xử lí xung đột để tạo khả năng thích ứng mà thôi, không đi sâu vào nội dung tâm lí nêu trên.

5/ Kỹ năng ra quyết định cho một sự thay đổi

Kỹ năng này liên quan đến 3 nội dung sau:

a) Kỹ năng phân tích tình hình, xác lập các căn cú cho việc ra quyết định cho một thay đổi cu thể (nhận diện bối cảnh, nhận diện đặc điểm của sự thay đổi, xem xét khả năng thực hiện sự thay đổi ở nhà trường mình và mức độ kết quả có thể đạt được);

b) Kỹ năng xác định những việc phải làm, cách làm và điều kiện, nguồn lực cần có để làm và thời hạn, xác lập các chỉ số để nhận diện và đánh giá kết quả, phương thức kiểm chứng kết quả... (đây chính là kỹ năng xây dựng kế hoạch hành động để thực hiện sự thay đổi ở nhà trường mình và khả năng kiểm chứng kết quả có thể đạt được của sự thay đổi);

c) Kỹ năng theo dõi, giám sát, đánh giá việc thực hiện các nội dung trong quyết định đã ban hành (tuy được xếp cuối nhưng được thực hiện thường xuyên trong suốt quá trình từ khi ban hành đến khi kiểm chứng được kết quả đạt được của sự thay đổi và duy trì được kết quả đó bền vững).

Trong bối cảnh thay đổi nói chung và đổi mới giáo dục nói riêng, mọi $\mathrm{CBQL}$ nhà trường ở các trường đại học cần được hình thành và phát triển năng lực thích ứng. Năng lực thích ứng có được nhờ vào nhiều yếu tố, có yếu tố thuộc về tâm lí, có yếu tố thuộc về khả năng phân tích và hành động trong bối cảnh cụ thể và có cả mức độ trải nghiệm cuộc sống của mỗi người. Tuy nhiên năng lực là sự tổng hợp tri thức, kỹ năng và ý thức thái độ được phát lộ thông qua khả năng thực hiện một hoạt động có hiệu quả nên việc bổ sung, cập nhật cho CBQL nhà trường những yếu tố liên quan đến các thành tố tạo nên năng lực thích ứng như khả năng dự báo, phân tích; khả năng hành động để thích nghi cũng là một trong những tiếp cận "tăng cường năng lực thích ứng cho $\mathrm{CBQL}$ nhà trường” trong bối cảnh đổi mới giáo dục ở Việt nam hiện nay.

\section{Lời cảm ơn}

Kết quả nghiên cứu trình bày ở đây được tài trợ bởi đề tài nghiên cứu khoa học có mã số $\mathrm{QG}$ 15.65 của ĐHQGHN; chúng tôi cảm ơn sự hỗ trợ của khoa Quản lí Giáo dục, Trường Đại học Giáo dục thuộc ĐHQGHN trong quá trình nghiên cứu đề tài này.

\section{Tài liệu tham khảo}

[1] Đặng Xuân Hải, Lê Thái Hưng, Đỗ Thị Thu Hằng, Thích ứng với thay đổi của cán bộ quản lí trường đại học trong bối cảnh đổi mới giáo dục hiện nay ở Việt Nam ( $\mathrm{NC}$ trường hợp ở ĐHQGHN); Tạp chí Khoa học ĐHQGHN, Nghiên cứu Giáo dục, tập 32, số 3, 2016.

[2] Heifetz, R. A., Linsky, M., \& Grashow, A. (2009). The practice of adaptive leadership: Tools and Tactics for changing your organization and the world; Cambridge, MA: Harvard; Business Press.

[3] Hòa Nhân, (2002); Tứ thư lãnh đạo (Đức thư; Ngôn thư; Lễ thư; Trị thư); NXB ĐH Tây Bắc; Bản dịch từ nguyên bản tiếng Trung của $\mathrm{NXB}$ Quân đội Nhân dân, 2008.

[4] Đặng Xuân Hải, Quản lý thay đổi trong giáo dục (giáo trình), NXB Đại học Quốc gia Hà Nội; 2015. 


\title{
Improving University Managers' Adaptability to Change in the Current Context of Education Reform in Vietnam
}

\author{
Dang Xuan Hai, Do Thi Thu Hang \\ VNU University of Education, 144 Xuan Thuy, Cau Giay, Hanoi, Vietnam
}

\begin{abstract}
The study of "university managers' adaptability to change in the current context of education reform in Vietnam - the case of Vietnam National University, Hanoi" was first presented in VNU Journal of Science: Education Research - Vol. 32, No. 3 (2016). Based on the study results, a framework of university managers' adaptability to change in the current context of education reform in Vietnam was proposed. According to the framework, university managers' adatability involves: a sense of changes; understanding the negative and positive effects of changes on oneself and on one's school; overcoming challenges in the most effective way. Most importantly, the adaptability of a manager is closely related to changes in the way he/she manages his/her institution.
\end{abstract}

Keywords: Identify, adaptability, framework of adaptability, criterion. 